\title{
THE HISTOLOGICAL APPEARANCES OF LATE SEGMENTAL COLLAPSE OF THE FEMORAL HEAD AFTER TRANSCERVICAL FRACTURE
}

\author{
Mary Catto, Glasgow, Scotland \\ From the University Department of Pathology, Western Infirmary, Glasgow
}

A third of severely displaced femoral neck fractures fail to unite, and of those in which sound bony union occurs, no fewer than 28 per cent later develop collapse of the upper, weight-bearing segment of the femoral head (Brown and Abrami 1964). Although the features of this condition have already been described by Santos (1930), Sherman and Phemister (1947), Phemister (1934, 1940, 1949), Coleman and Compere (1961) and Hulth (1961) amongst others, continuing controversy about the interpretation of the microscopic findings has encouraged me to present the findings in twelve patients. Histological sections and slab radiographs of serial coronal blocks of the excised femoral heads were prepared as described elsewhere in this issue of the Journal. Unfortunately it was impossible to remove the femoral head in one piece from two patients. Previous serial radiographs were examined except those of Case 3 which had been lost.

\section{CLINICAL FINDINGS}

The clinical information about these patients is summarised in Table I. All the patients were women, and all suffered displaced transcervical fractures treated by internal fixation. The fractures united and the patients, who had begun walking between ten and twelve weeks after the injury, had had no pain until one year three months to two years three months after the fracture. The onset of pain was usually accompanied by the appearance, for the first time, of the radiological changes of late segmental collapse. Later, pain and disability became severe enough to warrant prosthetic arthroplasty from one year eight months to four years six months after the fracture.

\section{PATHOLOGICAL FEATURES}

The tissue changes are described briefly in Table II. A more detailed description of a representative selection of these femoral heads is given below.

Case 4-The radiograph (Fig. 1) shows that the nail had been placed low in the head; the fracture united (Fig. 2) but there was a radiotranslucent line which is seen partly in the neck and passing on to the superior articular surface. The contour of the head is abnormal with flattening of the upper segment. The superior and inferior steps demarcating the area of collapse at the articular surface are more clearly seen in the slab radiograph (Fig. 3). On naked eye examination of the excised femoral head the cartilage appeared only slightly thinned and there was relatively little deformity of the contour. Microscopy showed that the whole head had undergone necrosis (Fig. 4). The marrow was necrotic, bone lacunae were empty and at the time of examination the greater part still consisted of dead bone (Fig. 5). The fracture, however, had united and revascularisation and reossification had progressed a short distance into the inferior part of the head but without reaching the foveal region. In the revascularised area, living bone could be seen on the surface of dead trabeculae (Fig. 6), which were abnormally thick, especially immediately behind the rather dense fibrous tissue at the edge of the revascularised area. In this fibrous tissue, however, trabeculae were scanty in some places; in others, strands of dead bone were of normal pattern and simply encased in fibrous tissue. There was no histological evidence of fragmentation or disruption of bone trabeculae in the collagen but this was found to a slight extent in the dead bone immediately beyond the line of revascularisation (Fig. 7). Trabecular fragmentation was seen much more strikingly in the 
MARY CATTO

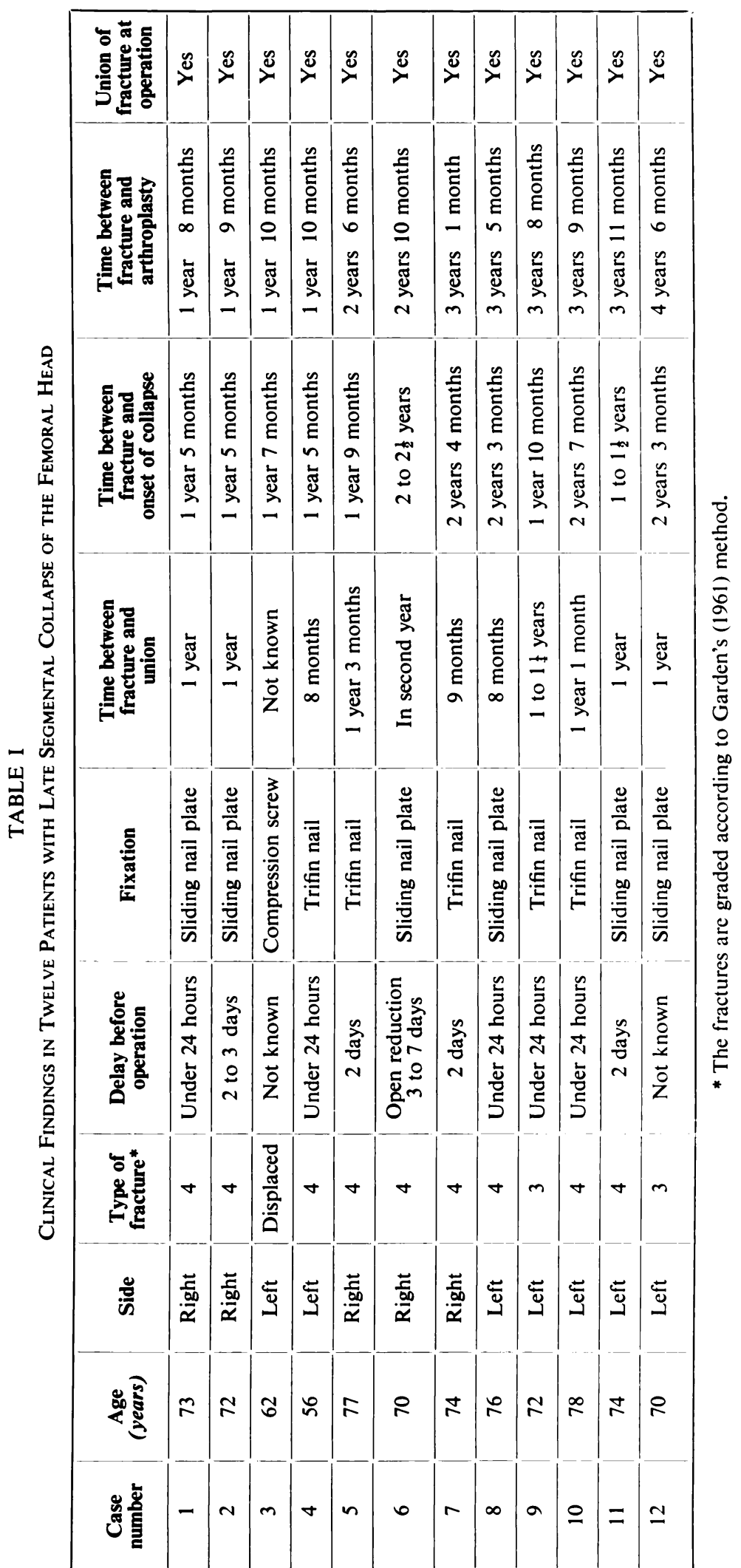

THE JOURNAL OF BONE AND JOINT SURGERY 


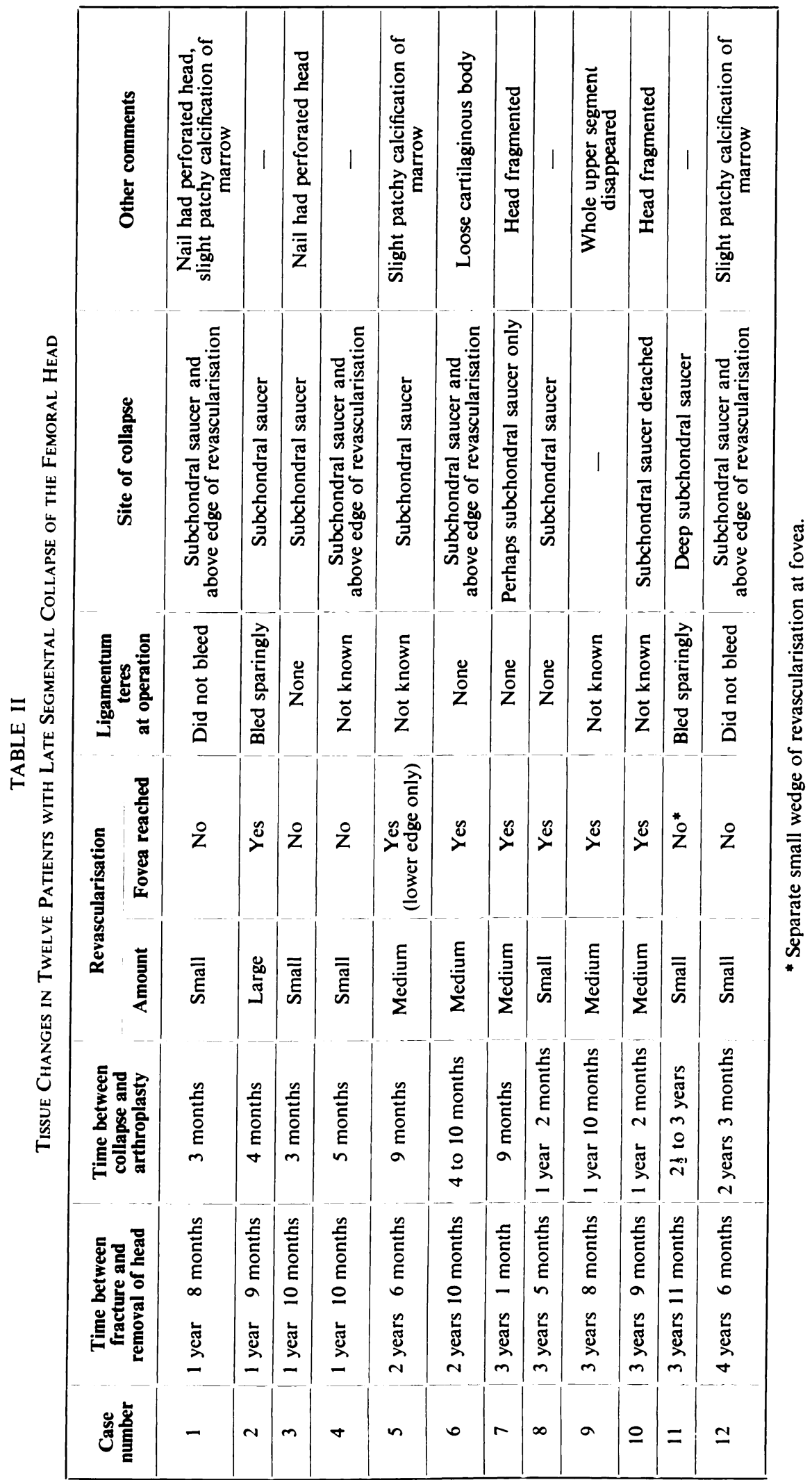

VOL. 47 B, NO. 4, NOVEMBER 1965 


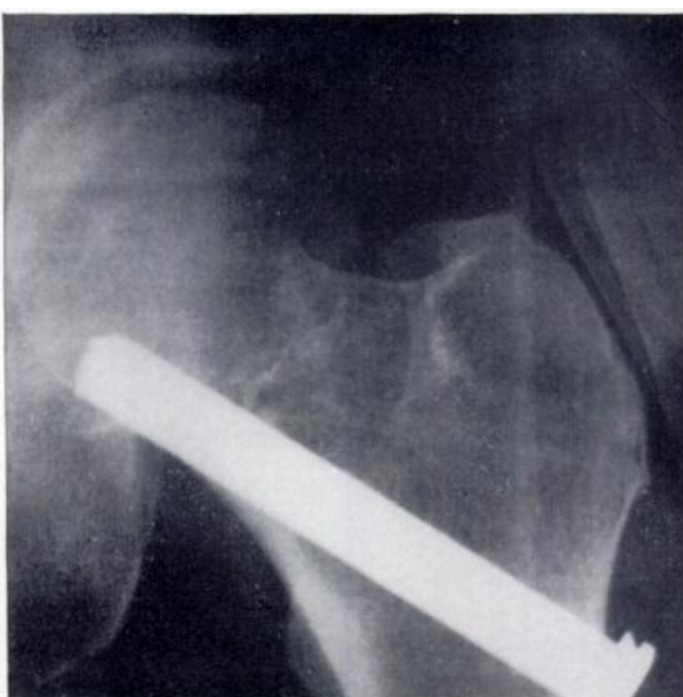

Fig. 1

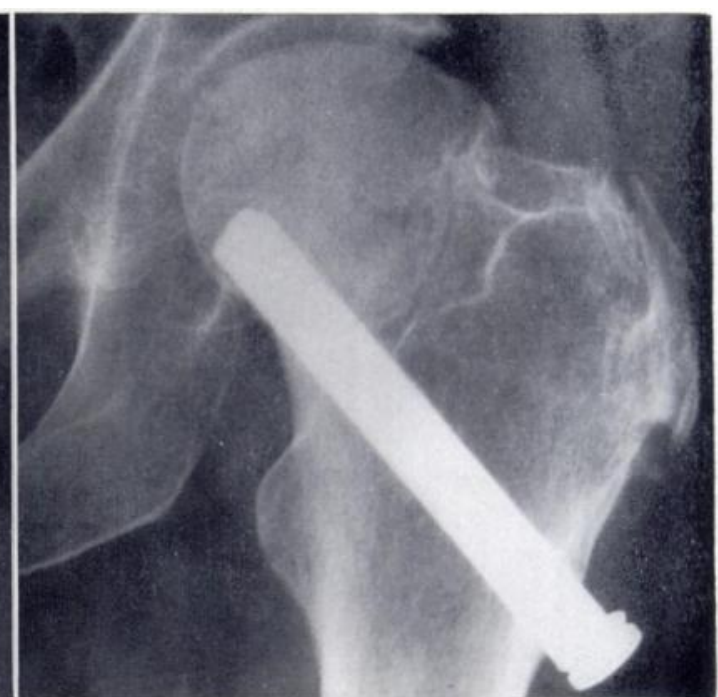

FIG. 2

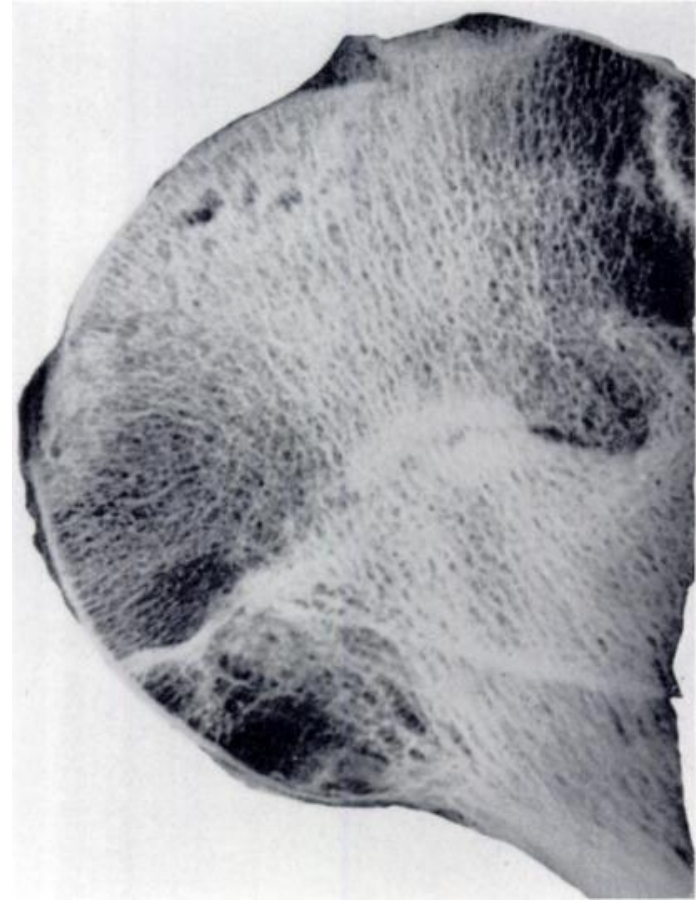

FIG. 3

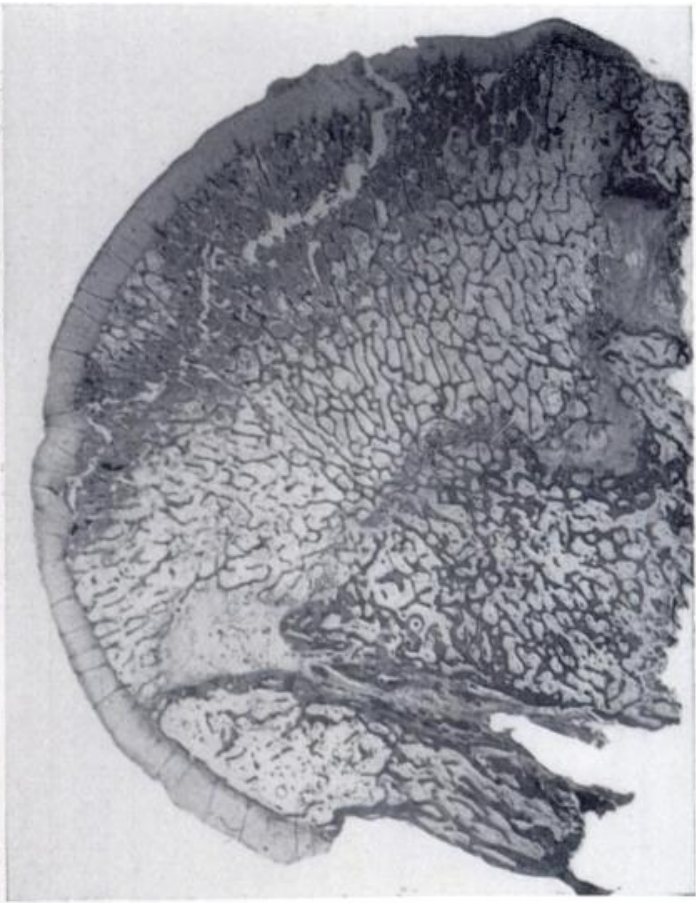

FIG. 4

Case 4. Figure 1-Radiograph after operation showing the very low position of the trifin nail. Figure 2Eighteen months after the fracture the radiograph shows collapse of the weight-bearing segment with a step in the articular surface. Figure 3-A slab radiograph showing the irregularity of the contour of the femoral nead caused by the collapsed segment. Faint irregular radiolucent lines mark areas of collapse both in a shallow subchondral saucer and deeper in the head. Figure 4-The histological preparation shows the superior shallow subchondral saucer which has separated within dead bone, the line of fibrous tissue separating dead from revascularised tissue and the thick bone trabeculae in the revascularised area. The nail track is seen inferiorly. Some bone trabeculae are seen bridging the fibrous tissue line in the upper head. 


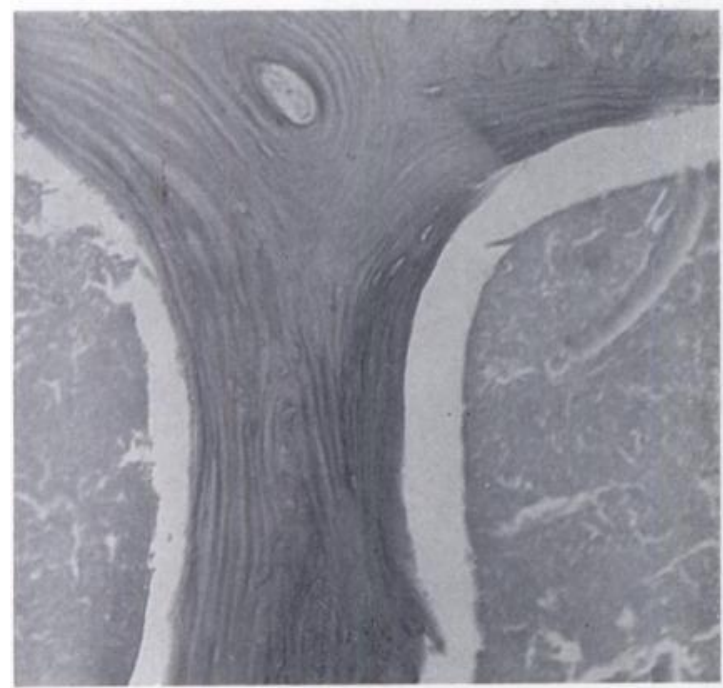

FIG. 5

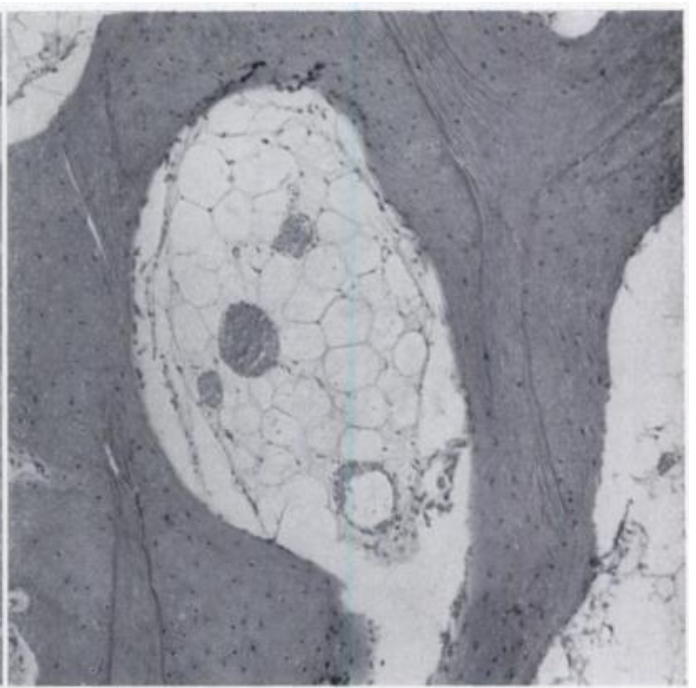

Fig. 6

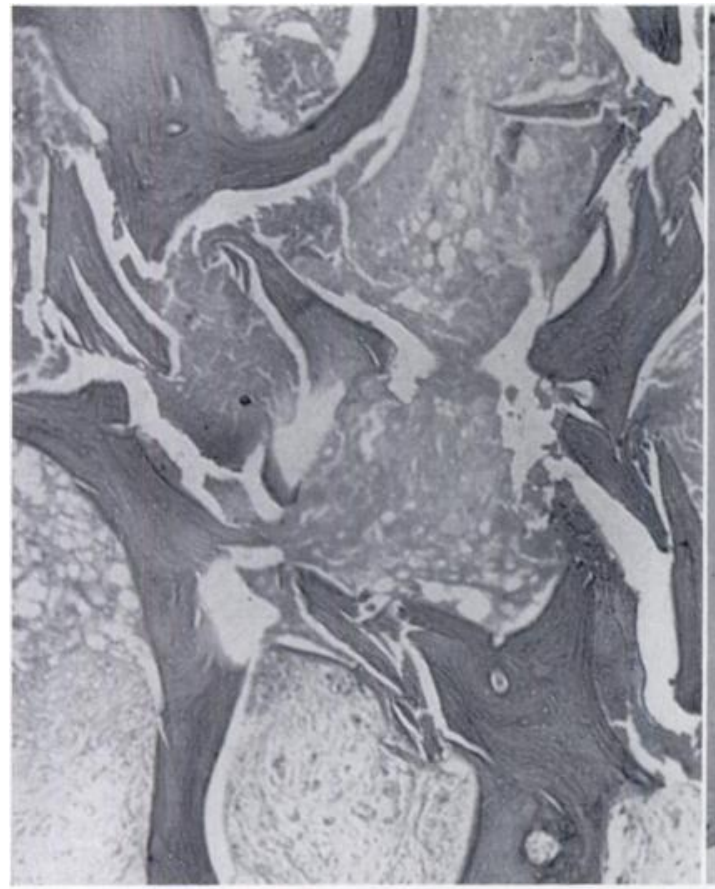

Fig. 7

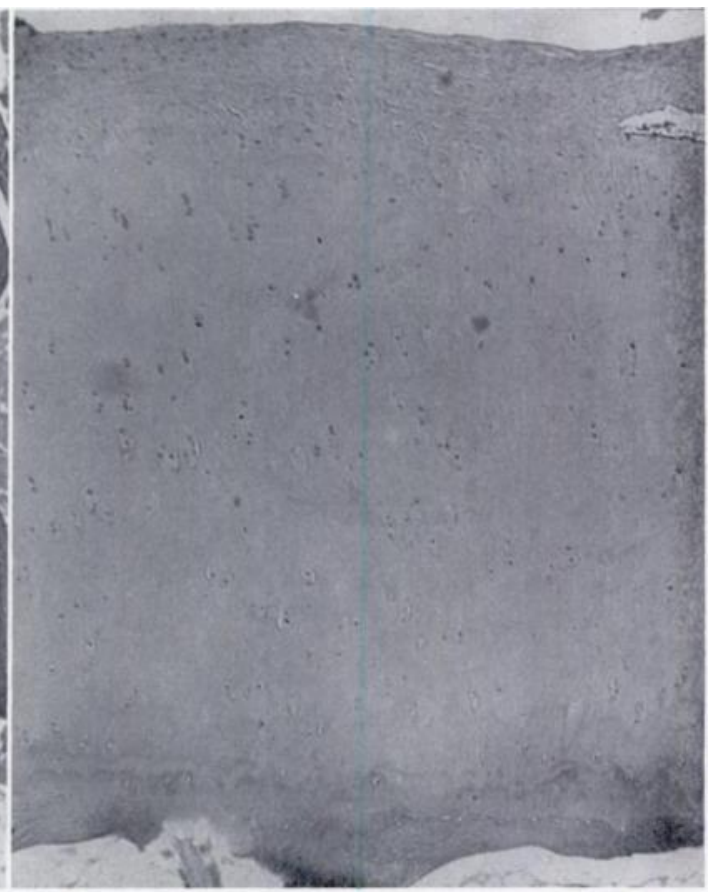

FIG. 8

Case 4. Figure 5-The dead subchondral bone is seen to have empty lacunae. There is fibrin in the dead marrow spaces. (Haemalum and eosin, $\times 130$.) Figure 6 - In the revascularised area living bone, containing osteocytes, is seen on the surface of dead bone with empty lacunae. The fatty marrow contains dilated blood vessels. (Haemalum and eosin, $\times 65$.) Figure 7-Dense fibrous tissue is seen around bone trabeculae at the most proximal part of the revascularisation zone and there is no evidence of osteoclasis or osteoblast activity here. Dead bone trabeculae have collapsed and fragmented proximal to the revascularisation zone. (Haemalum and eosin. 50.) Figure 8-Superficial cartilage has lost its hyaline appearance and become more fibrous. (Haemalum and eosin, 65.) 
region of separation of a shallow subchondral saucer within the dead bone of the upper head. Here, coagulated tissue fluid was present in the marrow spaces but nowhere was there evidence of calcification of marrow. In this patient, on comparing the histological preparation with

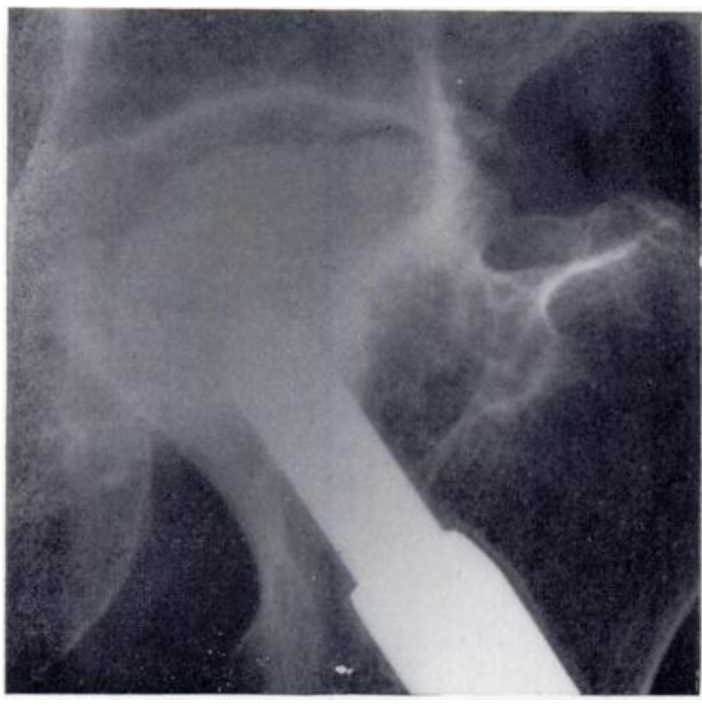

FIG. 9

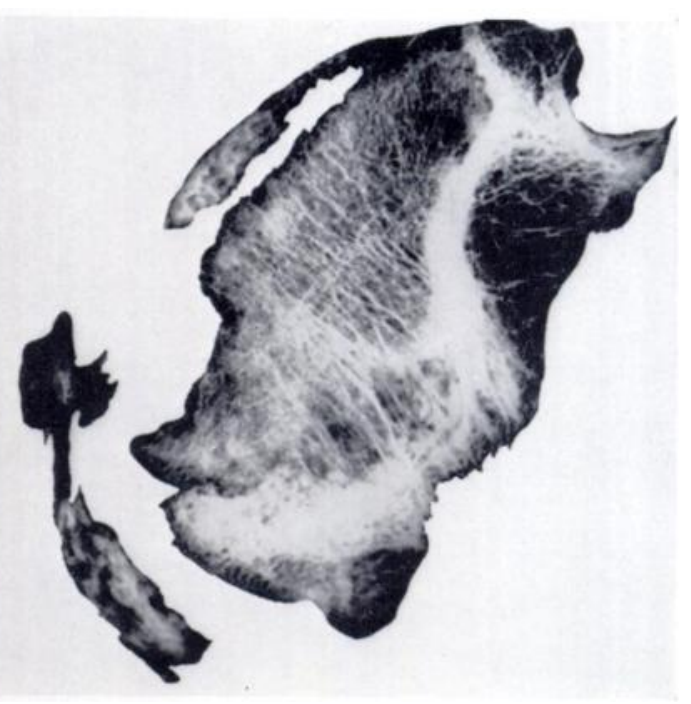

FIG. 10

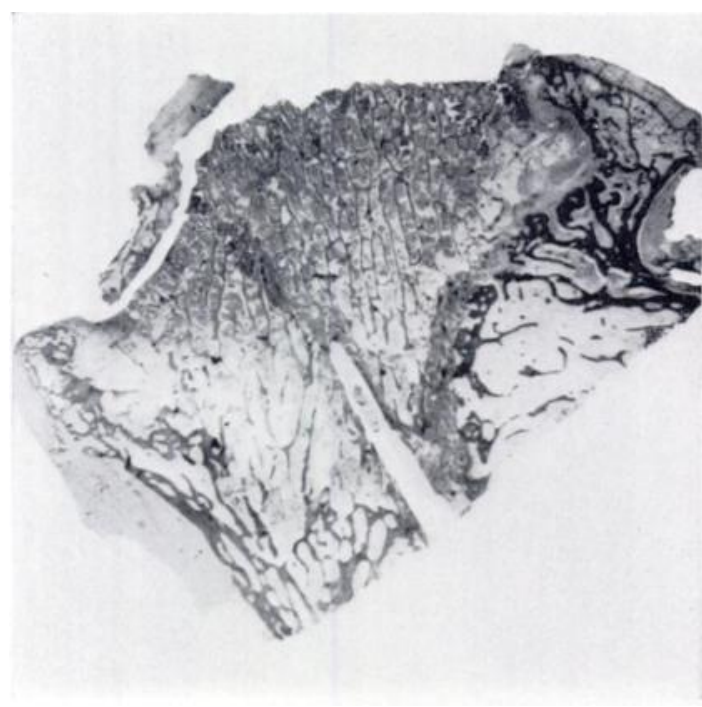

Fig. 11

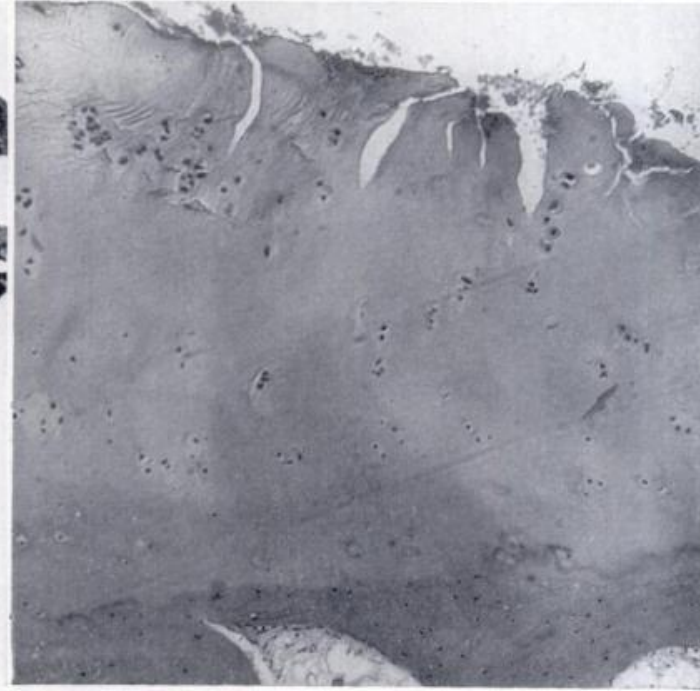

FIG. 12

Case 12. Figure 9-Radiograph fifty-two months after fracture showing solid bony union but collapse of the weight-bearing segment. A thin radiolucent line can be seen immediately beneath the articular surface of the femoral head as described in other forms of avascular necrosis by Norman and Bullough (1963). There are osteophytes at the periphery of the head. Figure 10-Slab radiograph. The cartilage and a thin subchondral bone saucer have separated. The dense line represents the broad trabeculae seen in Figure 11 at the edge of the revascularised zone. The greater part of the head remains dead. Bone trabeculae are seen bridging the fibrous tissue of the revascularised margin in the lower head. Figure 12-The articular cartilage is thin and fibrillated, with clumping of chondrocytes - the changes of osteoarthritis. (Haemalum and eosin, $\times 70$.)

the slab radiograph, it was evident that, of the possible causes of the increased density along the line of revascularisation, such as crushing and impaction of trabeculae, marrow calcification and reossification, it was reossification which appeared to play the important part. There 
was some loss of chondrocytes and fibrillation in the articular cartilage of the weight-bearing area. Elsewhere, some of the superficial cartilage had lost its hyaline appearance and was fibrocartilaginous (Fig. 8) but secondary osteoarthritic changes were not severe.

Case 12-This femoral head was removed four and a half years after fracture and tivo and a quarter years after segmental collapse was first seen radiologically (Fig. 9). The appearances were essentially the same as those of the previous case with regard to the extent of original necrosis and amount and pattern of revascularisation (Figs. 10 and 11). Some soft-tissue tags which appeared alive were present and may have become reattached and aided revascularisation from the neck; the vessels of the ligamentum teres clearly played no part because the foveal area remained necrotic. The greater part of the articular cartilage with a thin layer of attached bone had separated and, in places, the under-surface of this necrotic

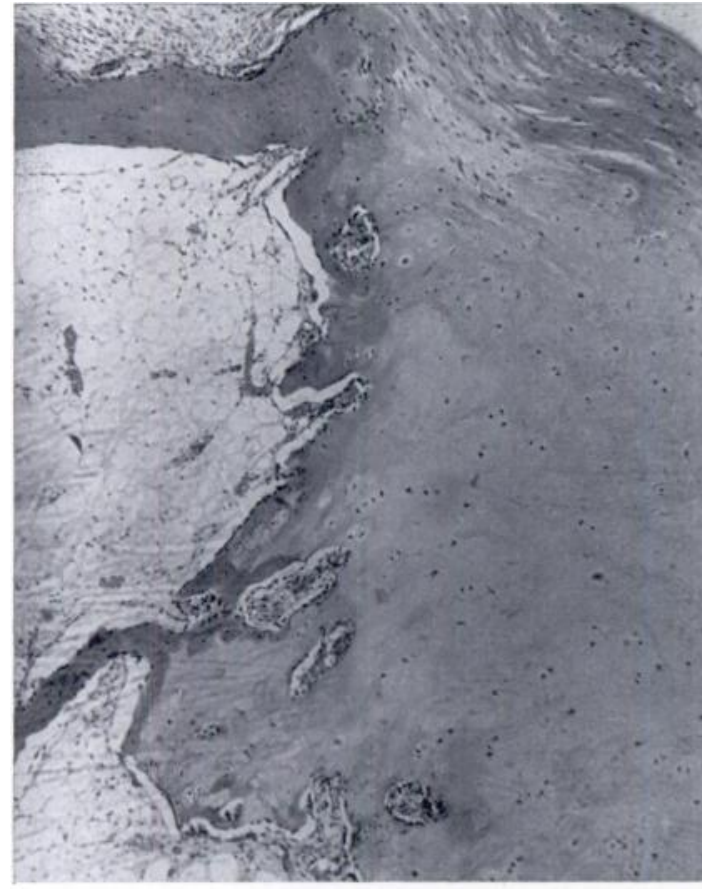

Fig. 13

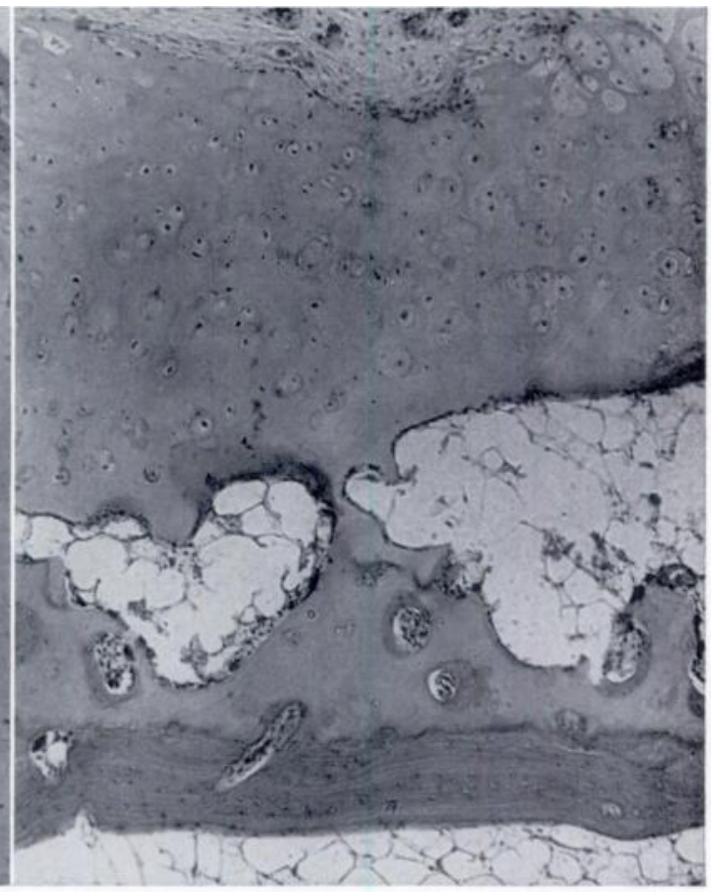

FIG. 14

Case 12. Figure 13-Resumption of endochondral ossification in the articular cartilage. (Haemalum and eosin, 65.) Figure 14 - Revascularisation and splitting of articular cartilage by adipose cells. The surface is covered by fibrous tissue. (Haemalum and eosin, $\times 60$.)

bone had become covered with fibrocartilage, that ubiquitous tissue which appears capable of forming in the most unpromisingly avascular sites. Fragmented trabeculae were seen in the exposed surface of the necrotic bone of the head and also to a lesser extent in the deeper part of the avascular bone adjacent to the line of revascularising granulation tissue.

In this case the femoral head was much deformed and flattened and there were secondary osteoarthritic changes involving the small amount of cartilage in the revascularised area at the periphery of the head (Fig. 12). There was a recrudescence of endochondral ossification of the articular cartilage (Fig. 13), formation of osteophytes, and splitting of the cartilage caused by its revascularisation (Fig. 14).

Case 2-A seventy-two-year-old woman had a prosthetic arthroplasty one and three-quarter years after her injury, segmental collapse having been recognised radiologically four months before (Fig. 15). The femoral head was well shaped and without evidence of severe 
osteoarthritis, there being only slight lipping of the periphery of the head superiorly (Figs. 15 to 17). While scattered central areas of bone necrosis within the trabeculae and some slight marrow fibrosis showed that the whole head had been dead there was now only a fairly

1

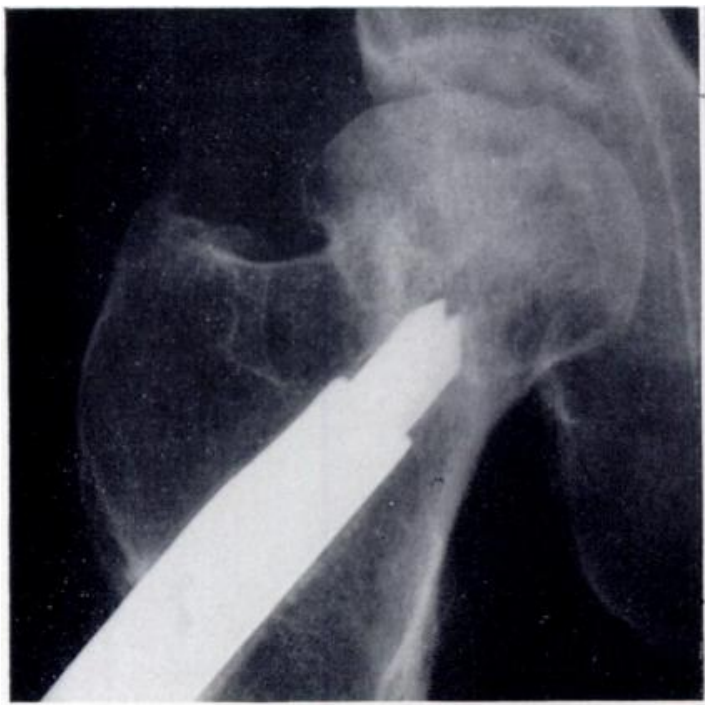

FIG. 15

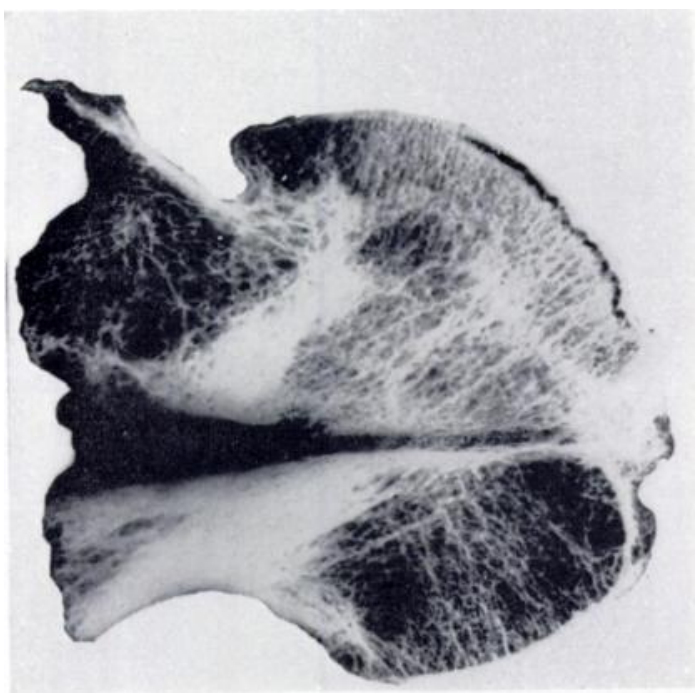

FIG. 17

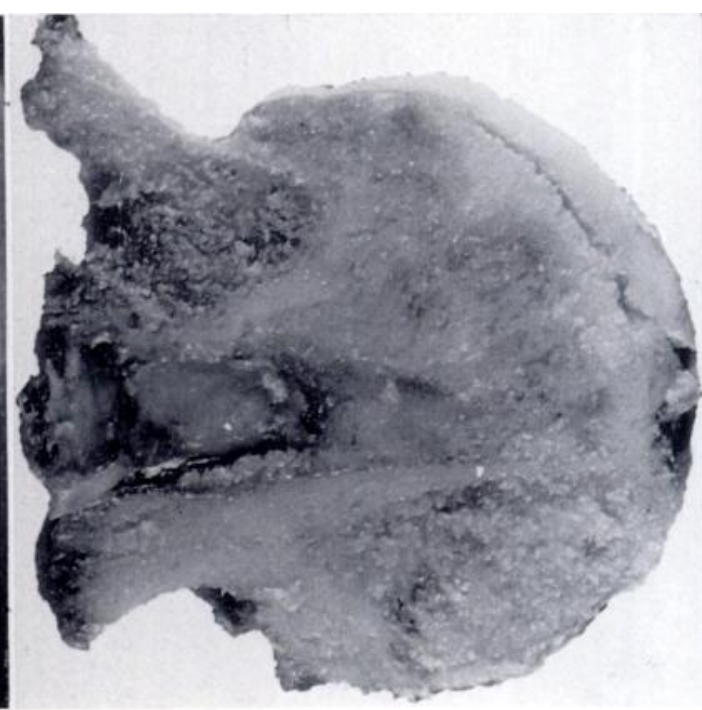

FIG. 16

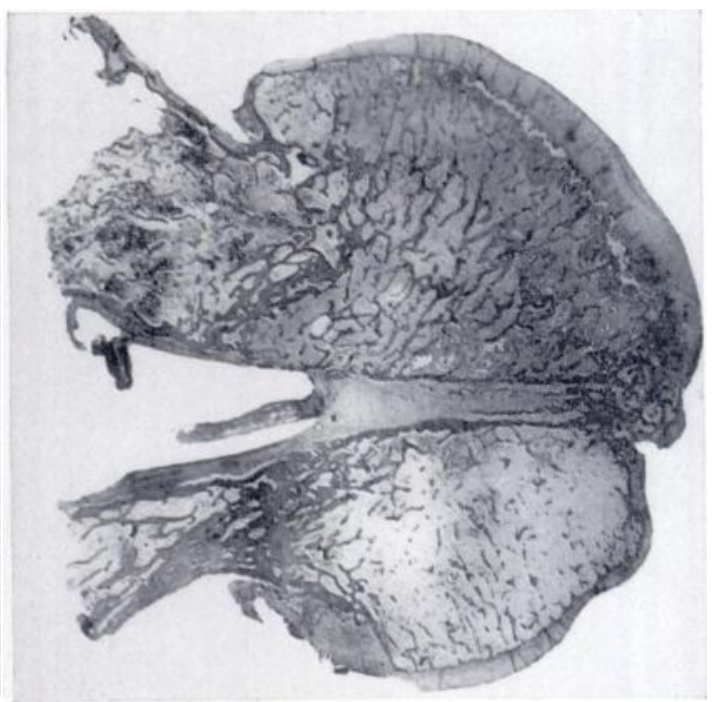

FIG. 18

Case 2. Figure 15-Radiograph twenty-one months after the fracture showing a small collapse of the upper segment of the femoral head. The nail has retracted. Figure 16-Photograph of the femoral head showing separation of the articular cartilage with a little dead bone attached. The very white bone is dead. The glistening line is the most proximal part of the area of revascularisation. Figure 17-Slab radiograph showing the area of persistently dead bone outlined by a dense line seen, in Figure 18, to consist of thick trabeculae in the most proximal area of revascularisation. The dense part at the junction of head and neck marks the fracture site.

The articular cartilage, although detached, retains its normal thickness.

shallow saucer of remaining dead bone in the upper weight-bearing area (Fig. 18). Separation had occurred once again through necrotic bone leaving a thin fringe of bone attached to the articular cartilage. In this specimen revascularisation had included the foveal area and 


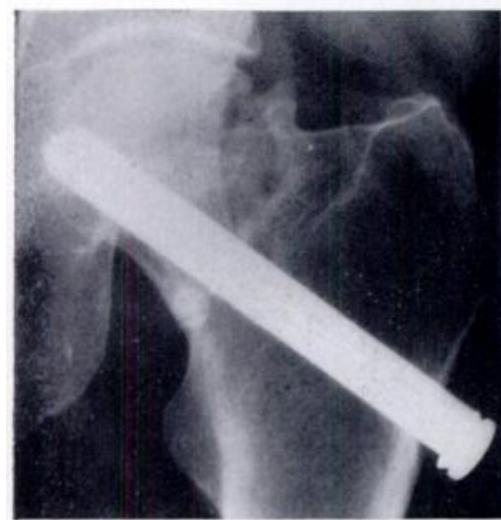

FIG. 19

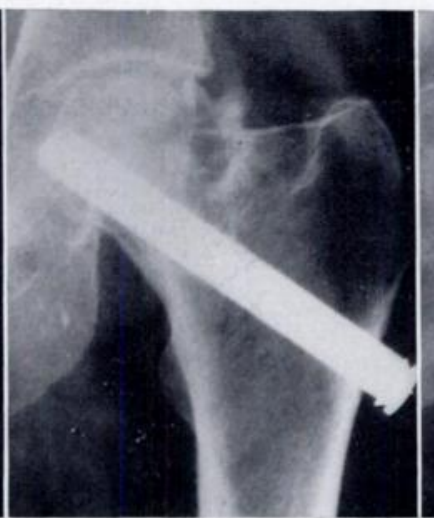

FIG. 20

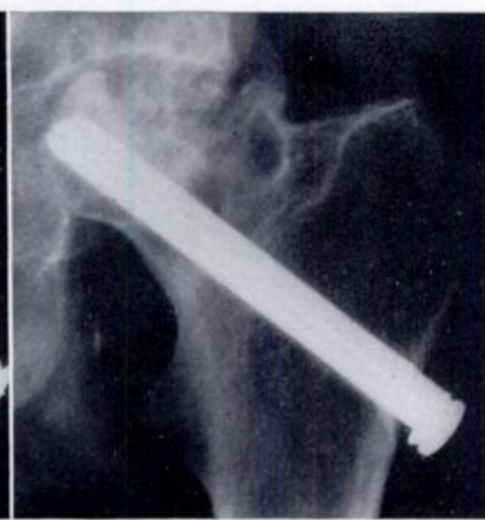

FIG. 21

Case 9-A series of radiographs showing the progressive collapse and disintegration of the upper femoral head one, one and a half and nearly four years after the fracture.

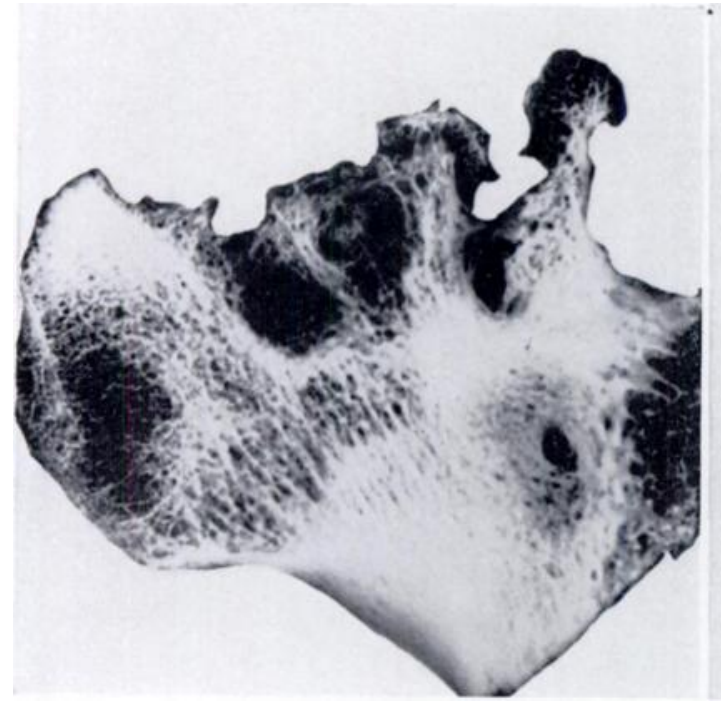

Fig. 22

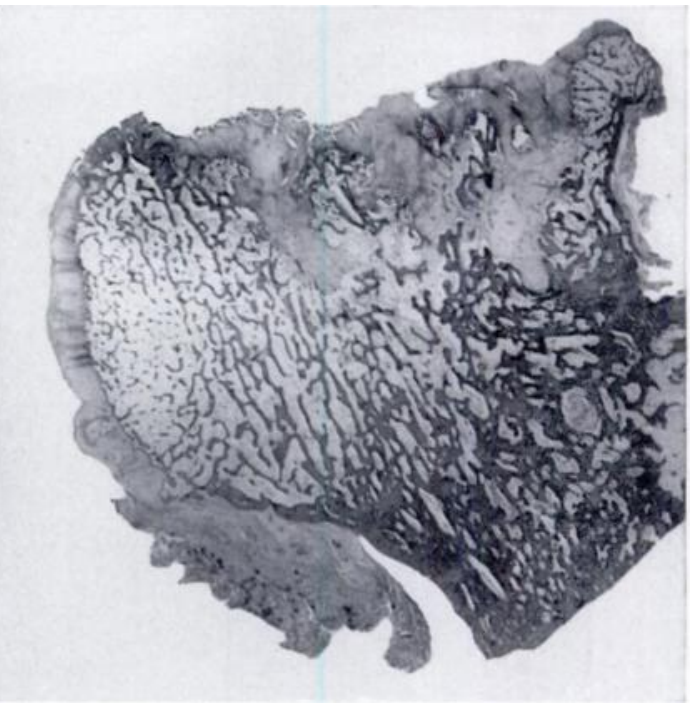

FIG. 23

Figs. 22 To 24

Case 9. Figure 22-The slab radiograph shows the disappearance of much of the upper segment of the femoral head with some osteophyte formation at the superior margin. Figure $23-$ Histological section shows that the surface of the upper segment is covered with fibrocartilage. There are many unusually broad trabeculae in the revascularised area. Figure 24-The broad trabeculae in the revascularised part of the head show cores of dead bone.

(Haemalum and eosin, 130.)

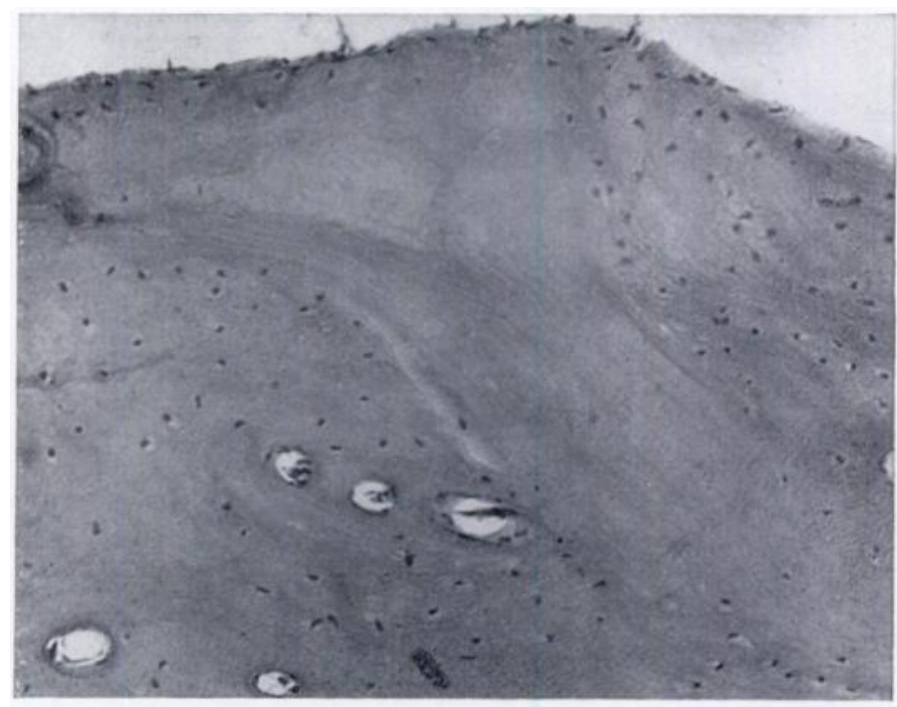

Fig. 24

VOL. 47 B, NO. 4, NOVEMBER 1965 
it was impossible to tell whether or not any vascular contribution had been made from the blood vessels of the ligamentum teres. The edge of the vascularised area was not densely fibrous but consisted of granulation tissue, and the adjacent ossified trabeculae, though thicker than normal, were not massively broadened.

Case 9-A seventy-two-year-old woman was found to have developed late segmental collapse one year and ten months after her fracture. She continued to bear weight for nearly two years after this and during that time there was increasing disintegration of the upper segment of the head with severe secondary osteoarthritic changes (Figs. 19 to 21). When the head was removed the upper, and presumably unrevascularised, segment had completely disappeared and the head showed a concavity covered by fibrocartilage (Figs. 22 and 23). The presence of central dead cores in broad bone trabeculae in the remaining part of the head (Fig. 24), combined with the radiological changes, are sufficient evidence to assume that there was late segmental collapse in which there had been separation and disintegration of the remaining unrevascularised bone. Such articular cartilage as remained showed severe degenerative changes, recurrence of endochondral ossification and osteophytic outgrowths at the margin of the head, although there was no diminution of thickness of the articular surface in the lower head.

\section{DISCUSSION}

In all twelve femoral heads there was convincing evidence that the whole head had been necrotic because of the widespread presence in the revascularised area of trabeculae with a central necrotic core. The area of dead bone in the trabeculae was bounded by a cement line and each lacuna was empty. These appearances have also been seen in the revascularised bone of young adults with caisson disease and contrast with the trabeculae in " normal " elderly subjects in whom, although osteocyte loss in cancellous bone may be extensive, it is usually patchy, as described earlier in this issue. The observations of Sherman and Phemister (1947), Phemister (1948) and Merle d'Aubigné and Cormier (1956) support the contention that the head is initially completely necrotic. There seems no reason to doubt that the necrosis occurred either at the time of the fracture or possibly at operation, because it is feasible that the blood vessels of the ligamentum teres may be damaged by manipulation or occasionally by accidental perforation of the fovea by a low-lying nail. Although an anastomosis has been demonstrated between the medial (ligamentum teres) and lateral epiphysial arteries sufficient to lessen damage by the nail (Claffey 1960, Brodetti 1960), nevertheless injury to the medial epiphysial vessels when they are the sole vascular supply, may cause a partial necrosis of the femoral head to become complete. Whatever the means by which it is brought about, it appears that, while the collapse is late and segmental, the necrosis is early and complete and the common use of the term "late segmental necrosis" is misleading. These femoral heads with late collapse do not correspond to the group with initial necrosis of only part of the head described by Woodhouse (1962) and Boyd and Calandruccio (1963).

In eight of the cases (see Table II) it was clear that the blood vessels of the ligamentum teres had played no part in the revascularisation process. In four patients no ligament was attached to the femoral head at all, and in a further four the revascularisation process had barely or not yet reached the foveal region. Usually there were live soft-tissue tags on the inferior aspect of the neck which had presumably become reattached and were playing some part in assisting revascularisation. The area of revascularisation in the early stages was often rather cup-shaped (Case 3, Figs. 25 to 27), there being more at the periphery of the head than at the centre and usually more at the inferior than the superior border. It has been shown elsewhere in this Journal that, when part of the head is kept alive by the vessels of the ligamentum teres, revascularisation of the dead area may be quite rapid and fracture union with a fully revascularised and undeformed head is possible. It is likely, however, that when the whole 


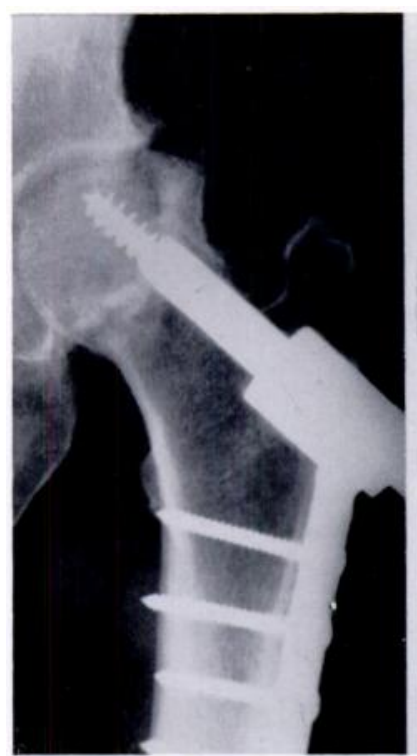

Fig. 25

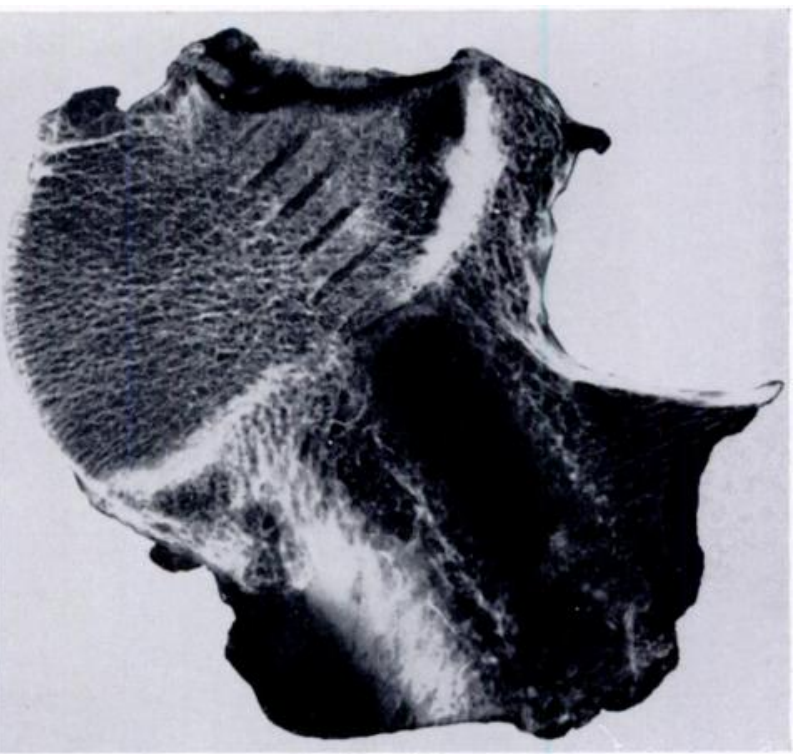

FiG. 26

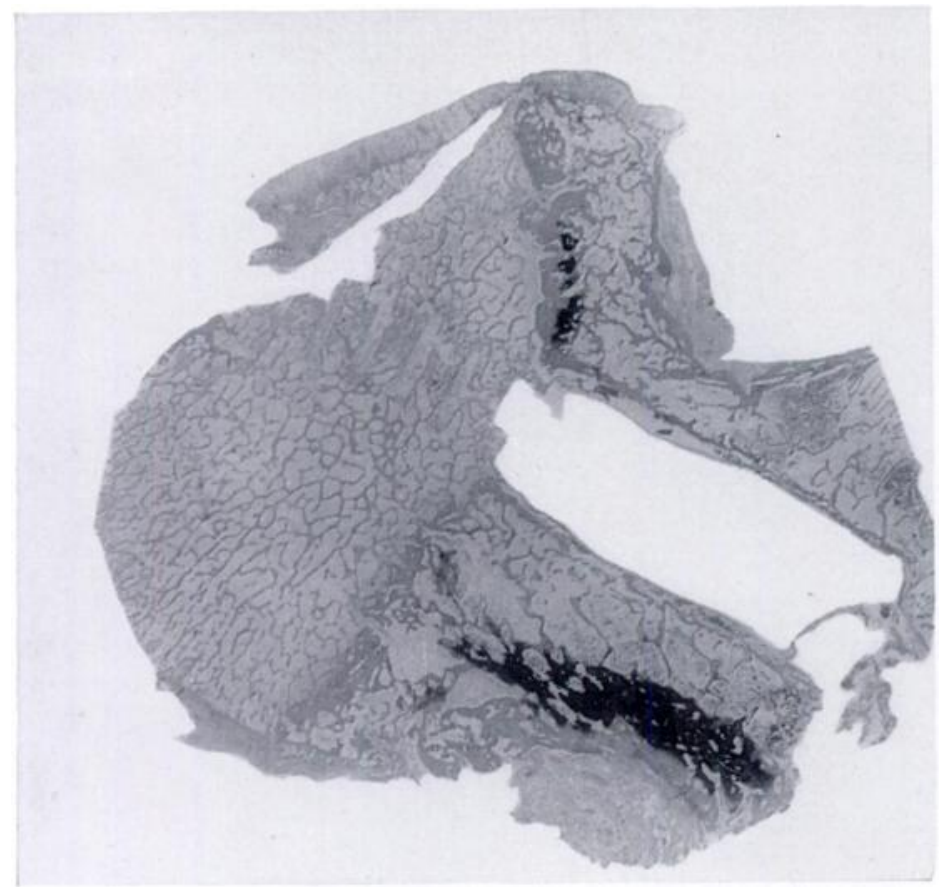

FIG. 27
Figs. 25 то 27

Case 3. Figure 25-The radiograph twenty-two months after a fracture shows a dense line marking the cup-shaped border of revascularisation. The upper segment is flattened. Figures 26 and 27-The slab radiograph and histological section show more clearly the boundary between dead and revascularised bone, which is marked by broad reossified trabeculae. The small subchondral saucer of bone has become partially detached. 
head has been necrotic and when there is little or no revascularisation from the foveal region, revascularisation across the fracture line is so slow and limited that it gives the opportunity for later collapse of the still necrotic bone, even though fracture union may have occurred. In one patient (Case 2) almost the whole head was revascularised within twenty-one months of the fracture which was an unusually rapid and complete process. In this specimen, although there was evidence that the whole head had been dead, it was possible that some contribution to the revascularisation had been received from the ligamentum teres. In Case 11 the vessels of the ligament had revascularised a very small subfoveal wedge of bone which was still separated from the area revascularised across the fracture line by a mass of necrotic bone.

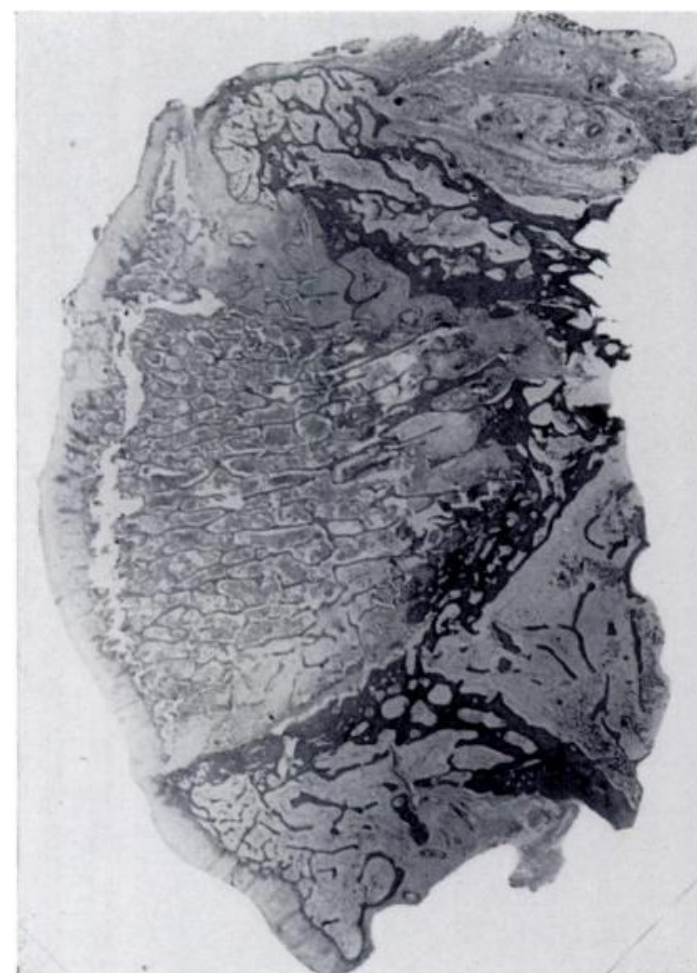

FiG. 28

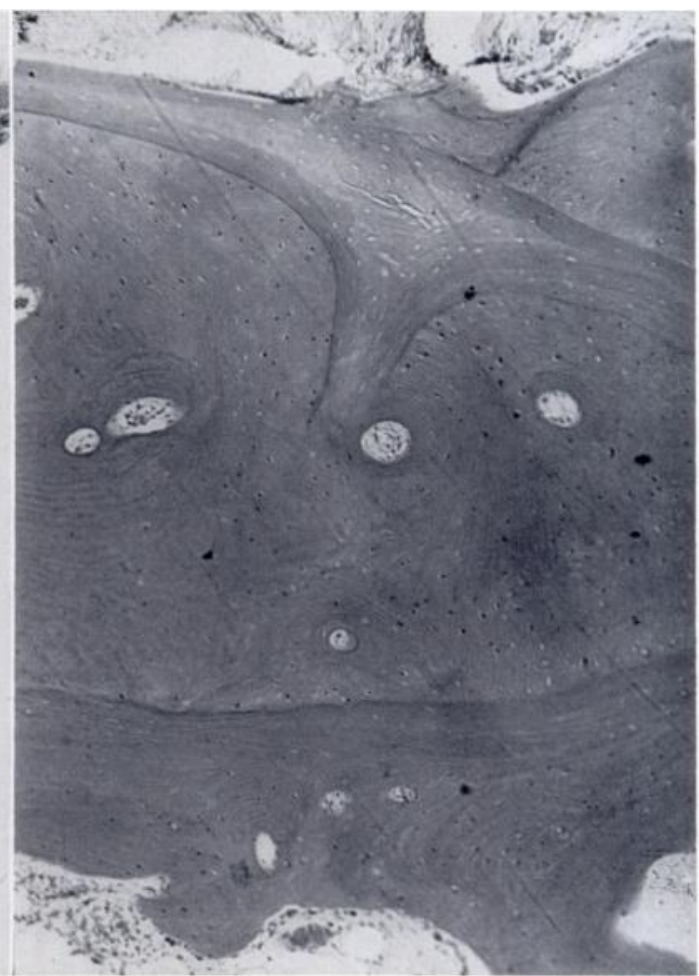

Fig. 29

Case 12. Figure 28-Very thick reossified trabeculae are seen bordering the dense fibrous tissue of the revascularisation front. There is partial separation of a subchondral saucer of cartilage and dead bone. Figure 29-Much new viable bone has been laid down on the surface of dead trabeculae near the edge of the revascularised area. (Haemalum and eosin, 65 .)

It was sometimes difficult to assess whether further revascularisation would have occurred if the head had been left in situ. In Cases 2 and 10 the line of revascularisation for the most part consisted of vascular loose fibrous tissue, and the reossified trabeculae behind this, while thicker than normal, were not massive. In the other femoral heads, however, most of the edge of the revascularised area was formed of rather dense collagen with a poor blood supply and it was hard to imagine that, unless the vascularity had improved, much further advance was possible. In these heads the reossified trabeculae near the revascularisation border were sometimes very greatly thickened (Case 12, Figs. 28 and 29).

It was difficult to understand why it was usual for so little of the head to be revascularised. It has been suggested that the process may be halted by a fracture at the junction of necrotic and revascularised bone, the band of fibrous tissue marking the site of reunion (Coleman and 
Compere 1961). However, in the femoral heads with late segmental collapse and in those with idiopathic necrosis (Patterson et al. 1964) the collagen between reossified and dead bone was frequently bridged by trabeculae (Figs. 4 and 11) having one end enclosed by living bone and the other in the necrotic zone. The presence of bridging trabeculae makes this an unlikely site for previous bony separation. While Phemister (1940) postulated that revascularisation halted as the result of the increased strain of returning function, other investigators have since suggested (Gallie 1956, Boyd 1957) that there is a critical size or physiological limit beyond which a bone infarct will fail to revascularise completely. While this may be partly true some other factor must be involved since in some femoral heads revascularisation barely crossed the fracture line. Similar slow and incomplete revascularisation is even less comprehensible in caisson disease (Kahlstrom, Burton and Phemister 1939) and idiopathic necrosis of the femoral head (Patterson et al. 1964), in which there is no fracture to delay the process.

Another very puzzling feature was the site at which collapse took place. Sherman and Phemister (1947) described collapse at the area of revascularisation from reduction in the size and strength of bone trabeculae by osteoclasis. In those femoral heads, however, although the amount of bone in the most proximal area revascularised was sometimes diminished, actual fragmentation occurred at two sites; sometimes in the dead bone immediately beyond the revascularisation border and almost always in a shallow subchondral saucer which separated within dead bone in the upper segment of the head (Table II) as described also in idiopathic femoral head necrosis (Patterson et al. 1964, Merle d'Aubigné 1964). It is suggested that this fragmentation and separation is in the nature of a stress fracture, the necrotic trabeculae having stood up to the strain of weight-bearing for some years before "giving way." The two conditions required to produce this are persistent bone necrosis and weight bearing; in some cases when the fracture unites in severe valgus the lower head bears weight, may fail to revascularise and collapses, while much of the upper head which is lateral to the acetabular fossa may revascularise and does not collapse.

From histological examination of these femoral heads some light can be thrown on the interpretation of the corresponding radiographs. The patients were actively weight-bearing and therefore failed to develop osteoporosis of the adjacent bone, so that the dead femoral head did not develop a relative increase of density as described by Phemister $(1939,1948)$. As has been observed by other authors (De Haas and McNab 1956, Boyd 1957, Bonfiglio and Bardenstein 1958, Bessler and Muller 1961), bone necrosis is not necessarily accompanied by any radiological change, and in the present twelve cases no abnormality was apparent until the onset of collapse of the articular surface. A true increase of radiographic density may be caused by reossification of dead bone with thickening of trabeculae (Bobechko and Harris 1960, Hulth 1961), by calcification of the marrow or by crushing down of fragmented trabeculae (Patrick 1960, Campbell 1961). In these femoral heads little calcification of marrow was seen and the main cause of the increased density was abnormally broad trabeculae in the revascularised area. Sometimes the heads showed patchy increased density, but in a few a well defined dense area was seen (Figs. 25 to 27). It must be emphasised that this line of increased density to $\mathrm{x}$-rays, although sometimes low in the head, never represented crushing of trabeculae at the original fracture site. The original fracture had healed and the dense zone was caused by the reossified trabeculae immediately distal to the line of revascularisation which were especially broad when the process had stopped.

In all cases the articular cartilage showed pathological changes. In the cartilage covering necrotic bone chondrocyte loss varied from being very slight to being almost complete and was most marked in the weight-bearing area. It was striking that, although the cartilage covering the collapsed segment was sometimes completely acellular, it nevertheless usually retained its normal thickness. In four femoral heads that were greatly flattened and deformed, very severe osteoarthritic changes had followed revascularisation of the subchondral bone at

VOL. 47 B, NO. 4, NOVEMBER 1965 
the periphery of the head. In places there was tangential flaking, fibrillation and loss of cartilage. Resumption of endochondral ossification at the articular surface was accompanied by the formation of osteophytes and sometimes of a new, more mushroom-shaped, articular surface, remnants of the old cartilage being embedded at some distance from the new surface (Figs. 12 to 14). As Sevitt (1964) has pointed out, those changes of the articular surface that give rise to symptoms are associated with revascularisation of the underlying bone. Revascularisation, however, is probably not responsible alone because these changes do not occur in femoral heads that revascularise rapidly enough to avoid late collapse. It is the combination of the falling-in of the joint surface and revascularisation that appears to give rise to arthritis.

\section{SUMMARY}

1. A study of late segmental collapse in twelve femoral heads shows that it may not develop until two and a half years after the fracture.

2. Until the articular surfaces had collapsed the patients usually had no symptoms. The fractures were united and there was no obvious radiographic evidence of ischaemic necrosis. 3. There was histological evidence that the whole of the femoral heads had been necrotic at one time. The term late segmental collapse is more appropriate than late segmental necrosis. 4. The blood vessels of the ligamentum teres played little or no part in revascularisation which, when it occurred, was almost entirely across the fracture line.

5. In only one femoral head was revascularisation approaching completion and apparently continuing. In the other eleven much of the head remained necrotic and the process appeared to have halted.

6. An increase in radiological density was caused by new bone laid down on unresorbed necrotic trabeculae and was most prominent behind the line of revascularisation when the process had halted.

7. Trabecular collapse was evident within dead bone. In ten of the femoral heads it occurred in the subchondral region and in four just beyond the junction of reossified and dead bone. 8. Osteoarthritic changes occurred in the cartilage covering revascularised bone at the periphery of the head, especially when collapse was severe.

It is a pleasure to acknowledge my indebtedness to Professor Roland Barnes and Mr J. T. Brown for help and constructive criticism in the preparation of this paper. I am grateful to the orthopaedic surgeons at the Western Infirmary, Glasgow, for free access to clinical information. Thanks are also due to $\mathrm{Mr}$ Matthew Findlay for the histological preparations and to Mr George Kerr for the photographs. Part of the expenses of this study were borne by a grant from the Advisory Committee on Medical Research of the Department of Health for Scotland.

\section{REFERENCES}

Bessler, W., and Muller, M. (1961): Le diagnostic précoce de la nécrose de la tête fémorale. Annales de Radiologie (Paris), 4, 21.

Bobechкo, W. P., and HaRris, W. R. (1960): The Radiographic Density of Avascular Bone. Journal of Bone and Joint Surgery, 42-B, 626.

Bonfiglio, M., and Bardenstein, M. B. (1958): Treatment by Bone-grafting of Aseptic Necrosis of the Femoral Head and Non-union of Femoral Neck (Phemister Technique). Journal of Bone and Joint Surgery, 40-A, 1329.

Boyd, H. B. (1957): Avascular Necrosis of the Head of the Femur. Instructional Course Lectures; American Academy of Orthopaedic Surgeons, 14, 196.

Boyd, H. B., and Calandruccio, R. A. (1963): Further Observations on the Use of Radioactive Phosphorus $\left(\mathrm{P}^{32}\right)$ to Determine the Viability of the Head of the Femur. Journal of Bone and Joint Surgery, 45-A, 445.

Brodetri, A. (1960): The Blood Supply of the Femoral Neck and Head in Relation to the Damaging Effects of Nails and Screws. Journal of Bone and Joint Surgery, 42-B, 794.

Brown, J. T., and ABrami, G. (1964): Transcervical Femoral Fracture. Journal of Bone and Joint Surgery, 46-B, 648.

Campbell, C. J. (1961): Aseptic Necrosis of Bone. Instructional Course Lectures: American Academy of Orthopaedic Surgeons, 18, 234. 
Claffey, T. J. (1960): Avascular Necrosis of the Femoral Head. An Anatomical Study. Journal of Bone and Joint Surgery, 42-B, 802.

Coleman, S. S., and Compere, C. L. (1961): Femoral Neck Fractures: Pathogenesis of Avascular Necrosis, Nonunion and Late Degenerative Changes. Clinical Orthopaedics, 20, 247.

DE HAAS, W., and MACNAB, I. (1956): Fractures of the Neck of the Femur; a Method of Assessing the Viability of the Femoral Head. South African Medical Journal, 30, 1005.

Gallie, W. E. (1956): Avascular Necrosis Involving Articular Surfaces. Journal of Bone and Joint Surgery, 38-A, 732.

Garden, R. S. (1961): Low-angle Fixation in Fractures of the Femoral Neck. Journal of Bone and Joint Surgery, 43-B, 647.

Hulth, A. (1961): Necrosis of the Head of the Femur. A Roentgenological, Microradiographic and Histological Study. Acta Chirurgica Scandinavica, 122, 75.

Kahlstrom, S. C., Burton, C. C., and Phemister, D. B. (1939): Aseptic Necrosis of Bone; Infarction of Bones in Caisson Disease Resulting in Encapsulated and Calcified Areas in Diaphyses and in Arthritis Deformans. Surgery, Gynecology and Obstetrics, 68, 129.

Merle d'Aubignte, R. (1964): Idiopathic Necrosis of the Femoral Head in Adults. Annals of the Royal College of Surgeons of England, 34, 143.

Merle D'Aubigné, R., and Cormier (1956): Nécrose traumatique de la tête du fémur en dehors des pseudarthroses. Revue de Chirurgie Orthopédique, 42, 246.

Norman, A., and Bullough, P. (1963): The Radiolucent Crescent Line-an Early Diagnostic Sign of Avascular Necrosis of the Femoral Head. Bulletin of the Hospital for Joint Diseases, $24,99$.

PAtrick, J. (1960): Avascular Necrosis and the Head of the Femur. Journal of Bone and Joint Surgery, 42-B, 650.

Patterson, R. J., Bickel, W. H., and Dahlin, D. C. (1964): Idiopathic Avascular Necrosis of the Head of the Femur. Journal of Bone and Joint Surgery, 46-A, 267.

Phemister, D. B. (1934): Fractures of Neck of Femur, Dislocations of the Hip, and Obscure Vascular Disturbances Producing Aseptic Necrosis of Head of Femur. Surgery, Gynecology and Obstetrics, 59, 415.

Phemister, D. B. (1939): The Pathology of Ununited Fractures of the Neck of the Femur with Special Reference to the Head. Journal of Bone and Joint Surgery, 21, 681.

Phemister, D. B. (1940): Changes in Bones and Joints Resulting from Interruption of Circulation. Archives of Surgery, 41, 436.

Phemister, D. B. (1948): Lesions of Bones and Joints Arising from Interruption of the Circulation. Journal of Mount Sinai Hospital, 15, 55.

Phemister, D. B. (1949): Treatment of the Necrotic Head of the Femur in Adults. Journal of Bone and Joint Surgery, 31-A, 55.

SANTOS, J. V. (1930): Changes in the Head of the Femur after Complete Intracapsular Fracture of the Neck. Archives of Surgery, 21, 470.

SevitT, S. (1964): Avascular Necrosis and Revascularisation of the Femoral Head after Intracapsular Fractures. Journal of Bone and Joint Surgery, 46-B, 270.

Sherman, Mary S., and Phemister, D. B. (1947): The Pathology of Ununited Fractures of the Neck of the Femur. Journal of Bone and Joint Surgery, 29, 19.

Woodhouse, C. F. (1962): Tetracycline Vascular Maps of the Femoral Head. Journal of Bone and Joint Surgery, 44-A, 1029. 